\title{
Belief ascriptions and social externalism
}

\author{
Ronald Loeffler
}

Published online: 7 April 2013

(C) The Author(s) 2013. This article is published with open access at Springerlink.com

\begin{abstract}
I outline Brandom's theory of de re and de dicto belief ascriptions, which plays a central role in Brandom's overall theory of linguistic communication, and show that this theory offers a surprising, new response to Burge's (Midwest Stud 6:73-121, 1979) argument for social externalism. However, while this response is in principle available from the perspective of Brandom's theory of belief ascription in abstraction from his wider theoretical enterprise, it ceases to be available from this perspective in the wider context of his inferential role semantics and his doctrines of scorekeeping and of the expressive role of belief ascriptions in discourse. In this wider context, Brandom's theory of belief ascriptions implies that Burge's argument trivially fails to have the disquieting implications for psychological explanations that it is widely taken to have. Yet since this is not trivially so, Brandom's theory apparently provides a false picture of our practice of interpreting belief ascriptions. I then argue that Brandom might as well accept the alternative picture of interpreting belief ascriptions that Burge's argument presupposes: even in the context of his overall project, Brandom's take on our practice of interpreting them does not afford belief ascriptions with the discursive significance Brandom claims they have.
\end{abstract}

Keywords Semantic externalism - Social externalism $\cdot$ De relde dicto belief ascriptions · Semantic holism - Linguistic communication - Interpretation · Psychological explanation $\cdot$ Mental content $\cdot$ Brandom $\cdot$ Burge

R. Loeffler $(\bowtie)$

Department of Philosophy, Grand Valley State University, MAK B-3 206, Allendale, MI 49401, USA

e-mail: loeffler@gvsu.edu 
(I) Between the late-60s and the $80 \mathrm{~s}$, in the context of the great debates about reference and singular thought, the contrast between de re and de dicto belief ascriptions (the de re-de dicto contrast, for short) was subject to intense discussion. ${ }^{1}$ It was argued that de re ascriptions demarcate beliefs of a special type that relate with particular intimacy to their referents. Today most people accept one or another version of this claim. More recently, Robert Brandom has looked at the de re-de dicto contrast from a different angle. While denying that de re ascriptions demarcate beliefs of a special type, he still argues that the de re-de dicto contrast is deeply significant: the contrast allows us to express-make explicit-our differences in linguistic understanding to each other in discourse. ${ }^{2}$

I shall outline the relevant aspects of Brandom's theory of the de re-de dicto contrast and show that this theory offers a surprising new perspective on Tyler Burge's original (1979) argument for social externalism. From this perspective, Burge's argument establishes externalism but straightforwardly fails to have the disquieting consequences for psychological explanations that it is widely taken to have. Yet while this perspective is in principle available if we accept Brandom's theory of belief ascriptions in isolation from the context of his larger theoretical enterprise-in particular, his holistic semantics and his theory of successful communication (his theory of scorekeeping) - it implies in this context that Burge's argument trivially fails to have these disquieting seeming consequences. And since this is not trivially so, Brandom's theory, in this context, is mistaken: it provides a false picture of our practice of interpreting belief ascriptions. Moreover, I shall argue that even in this wider context Brandom's theory does not, after all, afford the de re-de dicto contrast with the discursive significance Brandom claims it has: whether we interpret belief ascriptions as Brandom proposes or in accordance with the standard picture presupposed by Burge's argument, they fail to allows us to make differences in linguistic understanding explicit to each other in discourse. Accordingly, Brandom might as well accept this standard picture: the larger context of his overall enterprise does not provide him with any special theoretical or prudential reason for favoring his proposed alternative take on the de re-de dicto contrast over the standard picture Burge presupposes.

(II) The de re-de dicto contrast is often introduced as a contrast in logical form of belief ascriptions, revealing belief as either a two-place or a three-place relation. ${ }^{3}$ Take the unregimented ascription

\section{(1) Jones believes that water quenches thirst immediately}

The surface grammar of (1) disguises a systematic ambiguity in logical form, which the analyses of (1) as either de dicto or de re reveal. Analyzed de dicto, (1) has the form

\footnotetext{
1 I use the term 'de re-de dicto contrast' here exclusively to mark a difference between two types of belief ascriptions, not between two types of beliefs (so-called de re and de dicto beliefs).

2 Brandom does not deny that there are so-called de re beliefs-he calls them epistemically strong. He only denies that de re belief ascriptions classify these beliefs. According to him, every belief is, in principle, ascribable both de dicto and de re (e.g. Brandom 1994, p. 526). Brandom develops this theory of belief ascriptions most fully in his 1994: Chaps. 8 and 9. For further discussion, cf. especially Brandom (2002, Chap. 3; 2007, pp. 663-670; 2011, pp. 210-214).

${ }^{3}$ For a distinction between syntactic versus semantic de re ascriptions cf. e.g. McKinsey (1999, p. 521).
} 


\section{(2) Jones believes that water quenches thirst immediately}

or

$\left(2^{\prime}\right) \quad$ Believes $<$ Jones, that water quenches thirst immediately $>$

Thus analyzed, (1) specifies, in its oblique that-clause, a complete (truth-valued) propositional content or dictum-that water quenches thirst immediately-and represents Jones as standing in a two-place belief relation to that dictum. ${ }^{4}$ Analyzed de re, (1) has the form

\section{(3) Jones believes of water that it quenches thirst immediately}

or

\section{$\left(3^{\prime}\right)$ Believes <Jones, water, that $\Phi_{\text {water }}$ quenches thirst immediately>}

So analyzed, (1) represents Jones as standing in a three-place belief relation to, first, what per se appears to be the incomplete content of an open sentence (that it quenches thirst immediately or that $\Phi$ quenches thirst immediately), and, second, the natural kind water. Given the anaphoric relation between the pronoun 'it' and the term 'water' in (3), (1), thus analyzed, moreover represents water as the referent (the res) of the ascribed belief.

In general, de dicto ascriptions represent believers as standing in two-place belief relations to complete (propositional) contents, whereas de re ascriptions represent believers as standing in three-place belief relations to, on the one hand, incomplete (or at least incompletely specified) contents and, on the other hand, the individuals, properties, or kinds that these contents are about.

Cognitive verbs like 'believes that' prima facie create intensional contextscontexts in which the substitution of co-extensional terms for each other does not necessarily preserve the truth-value of the overall ascription. Accordingly, a wellknown substitutional test indicates whether ordinary belief ascriptions should be analyzed de dicto or de re (e.g. Quine 1956, pp. 181-182; Kaplan 1968, pp. 179-180; Burge 1977, pp. 341-342). Substitute into an ordinary ascription, such as (1), any co-extensional term for a term that, according to surface grammar, occurs in oblique context (for example, substitute ' $\mathrm{H}_{2} \mathrm{O}$ ' for 'water' into (1)). If the substitution does prima facie not necessarily preserve the truth-value of the ascription, the substituted-for expression ('water') occurs indeed in oblique context at the level of logical form, and the original ascription is de dicto. Otherwise, it is de re.

This way of introducing the de re-de dicto contrast is contentious in various respects, and also potentially at variance with some of Brandom's views on belief ascriptions. ${ }^{5}$ Yet, these points of contention and potential variance have no bearing on the argument I wish to make.

\footnotetext{
4 I shall use Quine's terms 'oblique' versus 'transparent' to refer to contexts that, at the level of logical form, are inside versus outside the that-clause of belief ascriptions (cf. Quine 1960, pp. 144-151).

5 For example, some (e.g. Cresswell 1985; Bach 1987, Chap. 10) argue against the systematic ambiguity of sentences like (1). Moreover, the relational analysis of de dicto and de re belief ascriptions is
} 
(III) Brandom develops his theory of the de re-de dicto contrast in the context of an elaborate semantic theory - a version of inferential role semantics-and a correlative theory of linguistic communication. I outline the relevant aspects of these theories in this and the next two sections.

Very briefly, Brandom assumes that a web of norms of material inference and material incompatibility, relating any atomic assertoric sentence to some (but not all) other atomic assertoric sentences of the language, partially constitutes the meaning of these sentences. ${ }^{6}$ For instance, the meaning of the English sentences

(4) Water quenches thirst immediately

and

(5) $\mathrm{H}_{2} \mathrm{O}$ quenches thirst immediately

is partially constituted by two norms of inference, one licensing the material inference from (4) to (5) and another one licensing the material inference from (5) to (4). Moreover, the meaning of (4) and

\section{(6) Water stirs thirst immediately}

is partially constituted by a norm certifying the mutual material incompatibility of (4) and (6). ${ }^{7}$

Brandom extends this material inferentialist approach to (atomic assertoric) sentence meaning to a substitutional approach to (non-logical singular and general) term meaning. According to this extension, certain norms governing the substitution of terms for other terms in the generation of material inferences and material incompatibilities constitute the meaning of these terms. For example, the meaning of the English terms 'water' and ' $\mathrm{H}_{2} \mathrm{O}$ ' is partially constituted by a norm according to which, for every occurrence of 'water' in an extensional context, substituting ' $\mathrm{H}_{2} \mathrm{O}$ ' for that occurrence generates a valid material inference, and by another norm according to which, for every occurrence of ' $\mathrm{H}_{2} \mathrm{O}$ ' in an extensional context, substituting 'water' for that occurrence generates a valid material inference. (Treating the two norms as a single conjunctive one, we may speak here of a single

Footnote 5 continued

contentious. For an alternative view cf. e.g. McKinsey (1999). Furthermore, assuming the relational analysis, the claim that one of the relata of belief is a (complete or incomplete) content, rather than, say, a (closed or open) sentence or the linguistic meaning of such a sentence, is potentially controversial. Again, Brandom regards the cognitive verb 'believes that' as an expressive locution and he may, accordingly, deny that it denotes any relation(s) (e.g. Brandom 1994, pp. 498-499). Finally, he prefers to supplant talk about belief with talk about (assertional) commitment (e.g. Brandom 1994, pp. 195-196, 596; 2000a, p. 174).

6 'Partially', because certain further norms determining, on the one hand, the proper use of an atomic assertoric sentence under certain non-linguistic observable circumstances (language entries) and, on the other hand, proprieties of non-linguistic actions (language exits) in the context of endorsements of the sentence also partially constitute the meaning of the sentence, according to Brandom.

7 'Material' in the sense that these inferences are valid, and these incompatibilities obtain, independently of sentences containing logical (formal) vocabulary. Brandom insists that the inference from (4) to (5), for example, is not enthymematic, that is, that it is valid independently of, say, the premise 'If water quenches thirst then $\mathrm{H}_{2} \mathrm{O}$ quenches thirst'. And similarly for the incompatibility between (4) and (6). 
symmetric substitution-inferential norm, governing the pair of terms 'water' and ' $\mathrm{H}_{2} \mathrm{O}$.') Similarly, the meaning of the general terms ' $x$ quenches thirst immediately' and ' $\mathrm{x}$ stirs thirst immediately' is constituted partially by a norm according to which, for every occurrence of ' $x$ quenches thirst immediately' in an extensional context, substituting the term ' $x$ stirs thirst immediately' for that occurrence generates a material incompatibility.

In general, an ordered pair of (non-logical singular or general) terms $<$ 'A', 'B'> is governed by what might be called a substitution-inferential norm iff every two sentences '___ A__ and '__ B__ ' (where 'A' and 'B' may occur several times in the respective sentences), such that (a) the latter sentence may be generated from the former in a single step by substituting ' $B$ ' for some occurrence(s) of 'A', and (b) the context(s) in which the substitution(s) of ' $\mathrm{B}$ ' for ' $\mathrm{A}$ ' take place are extensional, are in relation of valid material inference (with '__ $A$ _' as the premise and '__ B__' as the conclusion). Similarly, an ordered pair of (non-logical singular or general) terms $\langle$ 'A', 'C' $>$ is governed by what might be called a substitution-

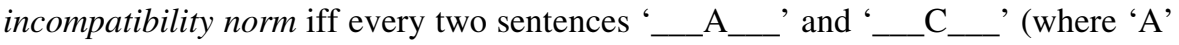
and ' $C$ ' may occur several times in the respective sentences), such that (a) the latter sentence may be generated from the former in a single step by substituting ' $\mathrm{C}$ ' for some occurrence(s) of ' $A$ ', and (b) the context(s) in which the substitution(s) of ' $\mathrm{C}$ ' for 'A' take place are extensional, are materially incompatible. Substitutioninferential and substitution-incompatibility norms (let's call them substitution norms) thus codify patterns of material inference and material incompatibility. Brandom's semantic thesis is that the meaning of each non-logical term is partially constituted by all the substitution norms relating the term to other terms (of the same syntactic category) of the same language. ${ }^{8}$

The details of this semantic theory do not matter for present purposes. For argument's sake, let's accept this theory without further discussion.

(IV) The substitution norms governing the terms of a language bind the speakers of the language. In light of them, speakers are obliged to accept in practice various substitution inferences from, and to recognize in practice various substitution incompatibilities with, the statements they make. Brandom calls such semantic obligations the substitutional commitments a speaker adopts in making a statement. Substitutional commitments are a type of normative status a speaker acquires in making a statement - a standard in light of which his subsequent linguistic and nonlinguistic behavior is assessable as correct or incorrect. ${ }^{9}$

The notion of a substitutional commitment links Brandom's theory of meaning to his theory of linguistic understanding. According to Brandom, a speaker's linguistic understanding — interpretation — of a (non-logical singular or general) term consists in part in the substitutional commitments the speaker acknowledges regarding the term, that is, in her treatment in practice of the term as governed by certain

\footnotetext{
${ }^{8}$ For the 'partially' cf. Fn. 6.

9 The speaker also adopts another type of semantic normative status by saying something: semantic entitlements. What he says permits him to make various further, materially compatible statements.
} 
substitution norms. ${ }^{10}$ The speaker understands the term in a certain way in part because, based on what she takes the substitution norms governing the term to be, she is disposed to draw various (valid or invalid) inferences from statements in which the term occurs in extensional position and disposed to treat (rightly or wrongly) these statements as incompatible with various other sentences, reachable by substituting for the term in question certain other terms of the same syntactic category. $^{11}$

Brandom thinks of a speaker's acknowledged substitutional commitments as normative attitudes, taken by the speaker, that play a causal role in the speaker's cognitive etiology. Drawing inferences is a causal process and treating pairs of statements as mutually incompatible is a causally efficacious state. Accordingly, qua dispositions to draw inferences and to treat pairs of statements as incompatible, acknowledged substitution-inferential and substitution-incompatibility commitments are part of the natural world of cause and effect (e.g. Brandom 1994, pp. 260-261; 2007, p. 669). However, Brandom denies that a purely non-normative (and, in this sense, naturalistic) account of acknowledged substitutional commitments can be given-for example, that acknowledged substitutional commitments reduce to dispositions to verbal behavior. On the one hand, acknowledging substitutional commitments intrinsically involves being sensitive to the semantic normative dimension of the terms in question, and Brandom denies that such sensitivity is fully explainable in non-normative terms (Brandom 1994, p. 33). On the other hand, Brandom's central "pragmatist" contention is that constellations of acknowledged substitutional commitments and other normative attitudes across speakers somehow institute or create the semantic norms themselves. And according to Brandom, these normative attitudes could not have this norm-instituting power if they reduced to purely natural states: the pragmatic theory of language use, characterizing these norminstituting attitudes, must itself be an irreducibly normative, rather than merely descriptive, pragmatics (e.g. Brandom 1994, pp. xii-xiii).

Brandom sometimes calls a speaker's interpretation of a term at a timeconstituted in part by the set of substitutional commitments she acknowledges regarding the term at that time-her conception of the term's meaning at that time (e.g. Brandom 2007, p. 669). It is the speaker's grasp of the term's meaning at that time. Yet of course, such interpretation may not, and usually is not, fully faithful to the objective meaning of the term. The term's objective meaning-which Brandom often calls the concept the speaker expresses by using the term (e.g. Brandom 2007, pp. 669-670)—is constituted in part by the objective substitutional norms governing the term, that is, by the substitutional commitments the speaker in fact adopts when using the term, and the speaker's acknowledged substitutional commitments may

\footnotetext{
10 'Implicitly in practice' in the sense that the speaker does not have to be able to articulate (make explicit) what she takes these purported substitutional norms to be, but only needs to be able to show her sensitivity to them by using the terms accordingly in discourse.

11 'In part', because her understanding of the term also partially consists in her propensities to endorse statements involving the term in response to perceptual inputs (language entries) and to act nonlinguistically in certain ways under certain circumstances based on such endorsements (language exits) (cf. Fn. 6).
} 
fail to capture some of these norms (her understanding may be incomplete) or she may acknowledge substitutional commitments to which no substitutional norm corresponds (her understanding may be deviant), or both.

(V) This last observation invites a version of the challenge, familiar from Fodor's and LePore's work, about the compatibility of semantic holism, such as Brandom's inferential role semantics and its correlative, holistic theory of linguistic understanding, with the possibility of successful linguistic communication (e.g. Fodor and LePore 1992). Given holism, any two speakers' interpretations of any (non-logical) term usually differ in certain respects at any time. Couched in Brandom's terms, the two speakers usually acknowledge different sets of substitutional commitments regarding the term at the time. It follows that the speakers usually understand all the sentences involving the term in different ways. Thus, they usually miscommunicate when they use these sentences: instead of sharing an understanding of what is said (and thus agreeing or disagreeing about its truth-value), the speakers simply talk past each other. Yet we do in fact communicate successfully most of the time. Therefore, any theory of linguistic understanding, such as Brandom's, that implies that we don't is false. ${ }^{12}$

(VI) We do not need to assess the merits of this challenge here. What matters is that Brandom takes the challenge very seriously and crafts, partially in reply to it, an elaborate theory of linguistic communication. At the heart of this theory is the rejection of the challenge's key assumption that successfully communicating speakers have to share an understanding of the linguistic performances exchanged. Instead, Brandom proposes, successfully communicating speakers have to keep track with how each interlocutor separately understands the sentences exchanged:

As long as there are differences in the collateral set of commitments with respect to which the content of the claim expressed by a sentence needs to be assessed, the sentence in one mouth means something different from what that

\footnotetext{
12 Brandom usually articulates this challenge in terms of differences in acknowledged 'collateral commitments' or 'auxiliary hypotheses' across speakers, that is, in terms of differences in the sets of assertoric sentences that the speakers also endorse (differences in their backgrounds of acknowledged assertional commitments; cf. e.g. the quote in the next section, and Brandom (2002, pp. 98-102) —apparently assuming that differences in such acknowledge collateral commitments imply differences in linguistic understanding. Yet this assumption is false. Brandom's theory allows that two speakers who acknowledge vastly different sets of assertional commitments nonetheless acknowledge the very same sets of substitutional commitments, and thus strictly speaking share an understanding of the term-tokens making up their linguistic performances. Consider the following simplified scenario: Speaker A assents to the two sentences ' $\mathrm{Fa}$ ' and 'Ga' and acknowledges an inference from ' $\mathrm{Fa}$ ' to 'Ga' (but not vice versa) whereas B assents to ' $\mathrm{Fb}$ ' and ' $\mathrm{Gb}$ ' and acknowledges an inference from ' $\mathrm{Fb}$ ' to ' $\mathrm{Gb}$ ' (but not vice versa). A and B thus acknowledge different assertional commitments (to ' $\mathrm{Fa}$ ' and ' $\mathrm{Ga}$ ' vs. ' $\mathrm{Fb}$ ' and ' $\mathrm{Gb}$ ' respectively) and different inferential commitments (from ' $\mathrm{Fa}$ ' to ' $\mathrm{Ga}$ ' vs. ' $\mathrm{Fb}$ ' to ' $\mathrm{Gb}$ ' respectively). However, they may understand the terms ' $\mathrm{F}$ ' and ' $\mathrm{G}$ ' in exactly the same way, by acknowledging just the substitutional commitment according to which every two sentences '___ $F_{\ldots}$ ' ' and '___ $G_{\ldots}$ ' ' (where ' $F$ ' and ' $G$ ' may occur several times in the respective sentences), such that (a) the latter sentence may be generated from the former in a single step by substituting ' $G$ ' for any occurrence(s) of ' $F$ ', and (b) the substitution(s) take(s) place in extensional context, are in relation of valid material inference. Thus, instead of articulating Fodor's and LePore's challenge in terms of differences in auxiliary hypotheses, it is better to articulate it directly in terms of differences in acknowledged substitutional commitments, which can be expected to pervade discourse independently anyway.
} 
same sentence means in another mouth. So even in the smooth untroubled case of communication, if you want to understand what I say, you have to be able to associate with it a sentence that in your mouth expresses the claim that the sentence I uttered expresses in mine. For your understanding it (your knowing what I have committed myself to) involves your being able to trace out the inferences that claim is involved in... in order to know what I am committing myself to. This means knowing... what claims its endorsement would preclude you, as well as me, from being entitled to, and so on. Apart from that capacity, you cannot extract information from what I say and cannot be said to understand it. (Brandom 1994, p. 510, cf. as well ibid., pp. 513, 586-601)

The idea here is that each successfully communicating speaker tracks, implicitly in practice, each interlocutor's linguistic understanding of the terms in use separately. In practice, each speaker keeps "separate books" - one book for each interlocutorrecording each interlocutor's acknowledged substitutional commitments regarding these terms. Due to this cognitive activity of separate bookkeeping, the participants can be said to understand each other-each knows how every interlocutor understands the statements exchanged-and hence to communicate successfully, despite their differences in linguistic understanding. Brandom calls this cognitive activity of separate bookkeeping scorekeeping. ${ }^{13}$

(VII) This brings us back to the de re-de dicto contrast. One reason for the significance of the contrast, according to Brandom, is that de re and de dicto ascriptions make explicit different aspects of this otherwise implicit scorekeeping activity $^{14}$ :

The suggestion is that the expressive function of de re ascriptions of propositional attitude is to make explicit which aspects of what is said express substitutional commitments that are being attributed [by the ascriber to the ascribee as acknowledged] and which express substitutional commitments that are undertaken [i.e. acknowledged by the ascriber herself]. The part of the content specification that appears within the de dicto 'that' clause is limited to what, according to the ascriber, the one to whom the commitment is ascribed would... acknowledge as an expression of what that individual is committed to. The part of the content specification that appears within the scope of the de re 'of' includes what, according to the ascriber of the commitment, but not necessarily according to the one to whom it is ascribed, is acknowledged as an expression of what the target of the ascription is committed to. (Brandom 1994, pp. 505-506. Cf. as well Brandom 2002, pp. 96-102; 2007, pp. 667-670)

This doctrine is my target. According to it, the chief discursive role of de re and de dicto belief ascriptions is that they allow us to articulate different aspects of our

\footnotetext{
13 The term is David Lewis' (cf. Lewis 1979). Yet Lewis and Brandom fill it with different content.

14 Another reason for this significance, according to Brandom, is that the de re-de dicto contrast yields an account of the representational dimension of thought and talk.
} 
otherwise implicit scorekeeping activity, and thus to make our differences in linguistic understanding themselves the explicit topic of the conversation. We interpret the oblique occurrences of terms in de dicto ascriptions not in accordance with our own acknowledged substitutional commitment, but rather in accordance with the substitutional commitments we take the ascribee to acknowledge. In this sense, de dicto ascriptions, so interpreted, make explicit how we take the ascribee to understand these terms. On the other hand, we interpret the transparent occurrences of the same terms in the corresponding de re ascriptions-reached from the original de dicto ascriptions by exporting these terms into transparent position-in accordance with our own acknowledged substitutional commitments regarding these terms. In this sense, these de re ascriptions, so interpreted, make explicit our own understanding of these terms. Thus by alternately ascribing a belief de re and de dicto, we convey how we ourselves, and how, according to us, the ascribee, understands the relevant terms.

For example, suppose that you do, and Jones does not, take water to be $\mathrm{H}_{2} \mathrm{O}$. According to Brandom, this means that you do, and Jones does not, acknowledge a symmetric substitution-inferential commitment regarding 'water' and ' $\mathrm{H}_{2} \mathrm{O}$ ', that is, a substitution-inferential commitment from 'water' to ' $\mathrm{H}_{2} \mathrm{O}$ ' and another one from ' $\mathrm{H}_{2} \mathrm{O}$ ' to 'water'. Suppose, moreover, that you know about this difference between yourself and Jones, that is, that the score you keep on Jones has registered it. Accordingly, you will interpret the oblique occurrence of 'water' in the de dicto ascription (2) based on Jones' deviating acknowledged substitutional commitments regarding 'water', as registered by your score, thus displaying Jones' understanding of the term. And you will interpret the transparent occurrence of 'water' in the corresponding de re ascription (3) based on your own acknowledged substitutional commitments regarding 'water', thus displaying your own understanding of the term.

(VIII) Let's pause for two comments. First, corresponding to the distinction between the normative status of being substitutionally committed by accepting a statement-being bound by the corresponding substitution norms-and the normative attitude of acknowledging certain substitutional commitments in accepting a statement we have a distinction between two senses of 'belief':

According to one usage [of 'belief'], I believe only what I think I believe, what I take myself to believe. I do not believe things behind my back; my sincere avowals are authoritative with respect to what I believe. According to another usage, however, I believe the consequences of my beliefs, whether I think I do or not. For my acknowledged beliefs can commit me to more than I acknowledge.... There can be tensions between these two ways of talking about beliefs: a narrow one tied to empirical dispositions to avow, the other more normative and expansive, closing beliefs under a consequence relation not limited by the believer's acknowledgement of it. (Brandom 1994, p. 507)

In one sense, what I believe by accepting a statement is delineated by what I'm prepared to acknowledge as consequences of the statement-hence by what I take to be the substitution inferential role of the statement, that is, by my acknowledged 
substitutional commitments regarding the terms in it. When taken in this sense, my belief thus plays a certain causal role in my cognitive etiology-since acknowledged substitutional commitments are part of the natural, causal order. In another sense, what I believe by accepting the statement is determined by the consequences I'm bound to acknowledge regarding the statement-hence by the substitutional commitments I objectively adopt when accepting the statement, whether or not I acknowledge them. In this sense, what I believe by accepting the statement plays a certain normative role in my cognitive life: it sets standards for assessing the proprieties of my linguistic and non-linguistic behavior.

Given Brandom's theory of belief ascriptions, the de re-de dicto contrast reflects this distinction between the two senses of 'belief' from an ascriber's point of view (e.g. Brandom 1994, pp. 507-508; 2007, pp. 669-670). Since the obliquely occurring terms in a de dicto ascription to another person, ${ }^{15}$ as interpreted by the ascriber, capture what the ascriber takes to be the ascribee's acknowledged substitutional commitments, and since acknowledged substitutional commitments are part of the natural, causal order, the de dicto ascription as a whole, thus interpreted, captures what the ascriber takes to be the causal role of the belief ascribed in the ascribee's cognitive life. It captures from the ascriber's point of view which inferences the ascribee is disposed to draw and which statements he is disposed to reject, given the belief ascribed. The correlative de re ascriptions to the same person, on the other hand, capture from the ascriber's point of view part of the normative significance of the belief ascribed, that is, they capture some of the substitutional commitments that the ascriber takes the ascribee to be bound to acknowledge, given the belief ascribed. The transparently occurring terms in the $d e$ $r e$ ascription, as interpreted by the ascriber, reflect the ascriber's own acknowledged substitutional commitments, hence what the ascriber takes to be the objective substitutional norms governing these terms. And since objective norms bind everybody, hence the ascribee in particular, the de re ascription as a whole, so interpreted, thus captures substitutional commitments (regarding these transparently occurring terms) that, according to the ascriber, the ascribee is bound to acknowledge given the belief ascribed-whether or not the ascribee acknowledges them in fact.

For example, the de dicto ascription (2), as interpreted by you, captures the belief ascribed to Jones as disposing Jones to de facto reject the inference from 'Water quenches thirst immediately' to ' $\mathrm{H}_{2} \mathrm{O}$ quenches thirst immediately', hence as playing in this regard a certain causal role. After all, your interpretation of the oblique occurrence of 'water' in (2) reflects Jones' failure to acknowledge a substitution-inferential commitment from 'water' to ' $\mathrm{H}_{2} \mathrm{O}$ ', and it thus captures the belief ascribed as one that would not prompt Jones to, for example, endorse the statement ' $\mathrm{H}_{2} \mathrm{O}$, quenches thirst immediately'. On the other hand, the corresponding de re ascription (3), as interpreted by you, displays the belief ascribed to Jones as involving certain normative statuses - in particular, as obliging Jones to, among

\footnotetext{
15 De dicto and de re self-ascriptions of beliefs do not bring out this contrast since, in this case, the ascriber's acknowledged substitutional commitments are the ascribee's.
} 
other, acknowledge as valid the inference from this belief to ${ }^{\prime} \mathrm{H}_{2} \mathrm{O}$ quenches thirst immediately'. After all, your interpretation of the transparent occurrence of 'water' in (3) reflects among other your own acknowledged substitution-inferential commitment from 'water' to ' $\mathrm{H}_{2} \mathrm{O}$ ', which you take to reflect an objective substitution norms governing these terms, and thus a norm that, according to you, binds Jones as well.

Second, this distinction between the two senses of the term 'belief' does not reflect a distinction between different kinds of belief, and in particular not between different kinds of content, according to Brandom, but a distinction between different perspectives on a single belief:

the de dicto ascription of a belief that $\Phi(\mathrm{t})$ and the de re ascription of a belief of $t^{\prime}$ that $\Phi(\mathrm{it})$ are not ascriptions of different beliefs. They do not ascribe beliefs with different contents. Rather, they specify the single conceptual content of a single belief in two different ways, from two different perspectives, in two different contexts of auxiliary commitments. (Brandom 2002, pp. 101-102. Cf. as well Brandom 1994, pp. 503, 584, 590-601.)

According to this doctrine, the ascriptions (2) and (3), for example, both ascribe the same belief to Jones. In particular, they individuate the same belief content, although from different perspectives of linguistic understanding. The de dicto ascription (2) captures what the ascriber takes to be Jones' grasp of that content, whereas the de re ascription (3) displays in part the ascriber's own grasp of the same content. Let's call this doctrine, that de dicto ascriptions and their correlative de re ascriptions all individuate the same belief, and in particular the same contentthough from different perspectives of linguistic understanding-the Perspectival Content Doctrine, or PCD. ${ }^{16}$

(IX) Let's turn to Burge's early (1979) argument for social externalism. Briefly, the argument runs as follows. Take Bert, a fictitious English-speaking medical layperson with arthritis. Bert has many true beliefs about arthritis: that he has it in his joints, that it is painful, that he has had it for many years, etc. Moreover, Bert is able to use the term 'arthritis' correctly under many discursive circumstances. Yet Bert falsely believes of arthritis that it may strike joints and thighs and that it has spread to his thighs. When Bert expresses this belief to his doctor, the doctor instructs him at time $t$ that arthritis may strike the joints only, and Bert immediately gives up these false beliefs and defers to the doctor. Still, intuitively, the de dicto ascription

\footnotetext{
16 Note that PCD implies that the occurrences of 'water' in (2) and (3) are recurrences of the same term, hence that they do not even to you reflect a semantic ambiguity of the English term 'water' - even though you interpret these two occurrences differently. Brandom defends this implication at length in terms of a sophisticated theory of anaphora. According to this theory, you treat the two occurrences of 'water' in (2) and (3) as anaphorically linked to each other (in Brandom's technical sense of anaphora), and therefore as recurrences of the same term, despite the variance in your interpretations of these occurrences (cf. Brandom 1994, Chaps. 7 and 8). Note also that PCD applies whether or not the ascriber acknowledges a symmetric substitution-inferential commitment regarding 'water' and ' $\mathrm{H}_{2} \mathrm{O}$ '. In either case, (2) and (3) ascribe the same belief — with the same content— to Jones, yet from different perspectives of linguistic understanding.
} 


\section{(7) Bert believes (prior to $t$ ) that he has arthritis in his thighs}

is true.

Next, Burge considers a twin-earth situation with a duplicate of Bert, Twert. Bert's and Twert's respective internal physical, behavioral, and phenomenal histories are type-identical up until $t$, as are much of their respective social environments, except that the medical experts in Twerts community use the term 'arthritis' unambiguously to classify the ailment afflicting Twert's joints as one that may also afflict the thighs. Thus, when Twert tells his doctor that the ailment he calls 'arthritis' may have spread to his thighs, the doctor is apprehensive (at $t$ ) and Twert continues to have the belief expressed. Crucially, despite Bert's and Twert's internal type identity up until $t$, the English de dicto ascription

\section{(8) Twert believes (prior to t) that he has arthritis in his thighs}

is intuitively false. Given the different expert uses of 'arthritis' in Bert's and Twert's respective communities and Bert's and Twert's deference to their respective experts, as well as given the apparent fact that, while Bert's crucial belief contradicts his doctor's at $t$, Twert's doctor potentially shares Twert's expressed belief at $t,{ }^{17}$ Bert (and his doctor) have, and Twert (and his doctor) lack, the concept, or notion, arthritis. Accordingly, Bert's and Twert's expressed beliefs just prior to $t$ differ in content. Whereas the concept arthritis partially constitutes the content of Bert's belief, a different concept-tharthritis (say) -constitutes the content of Twert's. That is, while (8) is false, the de dicto ascription

(9) Twert believes (prior to $t$ ) that he has tharthritis in his thighs

is true.

(X) Yet given Bert's and Twerts internal physical, behavioral, phenomenological, etc. type-identity prior to $t$ it follows that the beliefs ascribed by (7) to Bert and (9) to Twert are neither reducible to, nor narrowly supervenient on, states internal to Bert and Twert. Social factors external to Bert's and Twert's skin partially constitute the respective contents of these beliefs. On the other hand, states and events internal to Bert and Twert plausibly suffice to causally determine Bert's and Twert's intentional behavior - the behavior that their intentions to act appear to control. If so, Burge's social externalist conclusion yields the corollary that neither Bert's arthritis beliefs and Twerts tharthritis beliefs nor, contrary to how it appears, Bert's arthritis intentions and Twert's tharthritis intentions ever contribute to the causal determination of Bert's and Twert's respective intentional behaviors. Hence, no good psychological explanation should invoke these beliefs and intentions.

Yet this corollary seems unacceptable.

(XI) The vast majority of commentators interpret Burge's (1979) argument as based on two crucial assumptions, about the conditions of concept possession and the semantics of belief ascriptions respectively. First, the argument is taken to assume that a subject may grasp a concept $C$, and take the belief attitude towards a

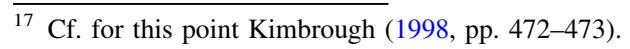


content in which $C$ figures, even if she has an incomplete or deviant grasp of $C$. For example, although prior to $t$ Bert has a deviant grasp of arthritis, hence of the content that he [Bert] has arthritis in his joints, as his deviating use of 'arthritis' prior to $t$ makes plain, he nonetheless takes the belief attitude towards that content prior to $t$. Call this the coarse-grained content assumption, or CGC. According to CGC, two subjects may have beliefs with the same content although their respective grasps of that content differ.

Second, the argument is taken to assume that oblique occurrences of terms in de dicto belief ascriptions represent the content of the beliefs ascribed as constituted by the very concepts that transparent occurrences of these terms express, but do per se not display the ascribee's grasp of these concepts. Call this the same semantic profile assumption, or SSP. ${ }^{18}$ According to SSP, the oblique occurrence of 'arthritis' in the de dicto ascription

\section{(10) Bert believes (prior to $t$ ) that he has arthritis in his joints}

represents the content of the belief ascribed as constituted by the concept arthritis, which is the very concept that the transparent occurrence of 'arthritis' in, say, the de re ascription

\section{(11) Bert believes (prior to $t$ ) of arthritis that he has it in his joints}

expresses. Yet (10) does per se not represent Bert's deviating grasp (prior to $t$ ) of the content that he has arthritis in his joints. ${ }^{19}$

SSP concerns the semantics of belief ascriptions in abstraction from our ordinary practice of interpreting them. Yet, clearly, Burge's argument also assumes an extension of SSP to the level of this practice. According to this extension, our ordinary interpretations of oblique occurrences of terms in de dicto ascriptions display the content of the beliefs ascribed as constituted by the very concepts that we take transparent occurrences of these terms to express, but do (cursive) per se not capture what we take to be the ascribee's grasp of these concepts-not even if we know independently how the ascribee grasps these concepts. For example, after having been instructed about arthritis and exposed to the tale of Bert, we interpret

\footnotetext{
18 I owe the term to Sandy Goldberg (in conversation). Burge himself endorses SSP in its Fregean guise, identifying concepts with Fregean senses (broadly speaking) and assuming that the referent of a term in oblique position is the sense that transparent occurrences of the term have. However, SSP is compatible with a Russellian identification of concepts with extensions (individuals and properties) (cf. Kimbrough 1998, p. 475).

19 "The relevant attributions... need not display the subject's error. They may be attributions of a true content. We can begin with a propositional attitude that involved the misconceived notion, but in a true, unproblematic application of it [such as (10)]" (Burge 1979, p. 82). This passage confirms that, according to Burge, de dicto belief ascriptions such as (10) do not display the ascribee's faulty grasp of the content ascribed-not even implicitly, nor even if the ascriber knows the ascribee's error-and that the chief way for an ascriber to display the error is via true ascriptions of beliefs whose content as a whole, as captured by the ascription's entire that-clause, explicitly displays the error (and is therefore false). For example, the true ascription (7) displays Bert's error because its entire that-clause explicitly captures Bert's mistaken identification of arthritis with ailments in the thighs, not because the oblique occurrence of 'arthritis' in (7) per se implicitly captures (what Brandom would call) Bert's faulty acknowledged substitutioninferential commitment to 'ailment in joints and thighs' (cf. Sect. XXI).
} 
the oblique occurrence of 'arthritis' in (10) as imputing to Bert what we take to be the concept arthritis - which we know to be true of certain ailments in the joints and false of any ailment in the thighs - and (10) as a whole as representing Bert to have a belief involving this concept. But our interpretation of the oblique occurrence of 'arthritis' in (10) does per se not capture Bert's deviating grasp of arthritis, even though we know independently of Bert's deviating grasp. Instead, it reflects our own more or less accurate grasp of arthritis, just as transparent occurrences of 'arthritis' do.

CGC and (the extension of) SSP are crucial for giving rise to the corollary. What determines Bert's intentional behavior in arthritis-related matters is his idiosyncratic grasp of the concept arthritis - the sum total of his propensities to (mis)apply this concept to various token ailments, to employ it in various true or false general arthritis beliefs, to draw various valid or invalid inferences involving it, to acknowledge various obtaining or non-obtaining incompatibilities based on it, etc. Thus, if (10), as interpreted by us in accordance with the extension of SSP, imputes what we take to be the concept arthritis to Bert, and is true of Bert-which is what CGC allows-yet fails to capture Bert's idiosyncratic grasp of this concept (it only reflects our own grasp of it), (10) fails to capture the psychological state it correctly ascribes to Bert as playing a causal role in the determination of Bert's intentional arthritis-related behavior. As ascribed, this state is no such determinant.

(XII) Importantly, most commentators on Burge's (1979) argument-supporters as well as critics-agree that (the extension of) SSP is both correct and theoretically innocent, that is, that it accurately describes, independently of controversial theoretical assumptions, our ordinary practice of interpreting belief ascriptions and our usual intuitions about their meaning. ${ }^{20}$ To be sure, supporters of Burge's (1979) argument occasionally offer justification for this interpretive practice. For example, Burge himself argues that a general practice of reinterpreting oblique occurrences of terms in de dicto ascriptions, for the sake of capturing the ascribee's idiosyncratic grasp of concepts, would "proliferate terminology without evident theoretical reward" (Burge 1979, p. 94)—evidently assuming that such reinterpretation would always require the introduction of new terms. However, such justification is not meant to guide or correct our ordinary interpretive practice, but merely to vindicate what we always already do, regardless of justification.

Given this wide-spread agreement regarding SSP, the debate concerning Burge's (1979) argument and its supposed corollary largely focuses on CGC, that is, on whether, for instance, the ascription (10), interpreted in accordance with (the extension of) SSP by us (who know that arthritis does not strike the thighs), is true

\footnotetext{
${ }^{20}$ Critics of SSP include Loar (1988), Bach (1988), and Patterson (1990). However, Loar explicitly agrees that we interpret ascriptions such as (7) and (10) in accordance with SSP, and merely argues that common sense psychological explanations individuate beliefs internalistically and by their psychological roles, rather than via de dicto ascriptions (interpreted in accordance with SSP). And Bach (1988) and Patterson (1990) agree that SSP reflects our ordinary interpretive practice in most cases, including, it seems, (7) and (10). They merely argue, focusing on other cases (conjured up in Burge's revised (1986a) argument, in the case of Bach) that we sometimes do not interpret de dicto ascriptions in accordance with SSP. For discussion cf. Goldberg (2002).
} 
despite Bert's idiosyncratic use of 'arthritis' prior to $t$. One side argues that (10), so interpreted, is false. Members of this camp usually reject CGC, regard Burge's argument for externalism as unsound, and mainly grapple with accounting for the mismatch between (10), so interpreted, and the belief, if any, ascribed to Bert. ${ }^{21}$ The other side maintains that (10), so interpreted, is true. Members of this camp usually accept CGC, regard Burge's argument for semantic externalism as sound, and mainly grapple with domesticating the apparently untenable corollary. ${ }^{22}$

(XIII) Let's assess Burge's argument from the perspective of Brandom's theory. Brandom accepts CGC. This follows from his theory of belief ascriptions plus his commitment to PCD. To see so, consider the de dicto ascriptions

\section{Bert believes (prior to $t$ ) that arthritis afflicts the joints}

and

\section{(13) Bert's doctor believes (prior to t) that arthritis afflicts the joints}

as interpreted by some idealized scorekeeper, whose score accurately captures all of Bert's and all of Bert's doctor's respective acknowledged substitutional commitments regarding 'arthritis' at the moment prior to $t$. (The idealization isn't crucial for my argument, but it drives the point home more perspicuously.) According to Brandom, both ascriptions, as interpreted by this scorekeeper, are true. ${ }^{23}$ Moreover, each ascription accurately captures via its oblique occurrences of 'arthritis', Bert's and the doctor's respective grasps of arthritis, hence their respective acknowledged

\footnotetext{
21 This group divides into two camps. Members of the radical camp argue that the implications of externalism show that folk psychology in general, and the belief ascription (7) (interpreted in accordance with the extension of SSP) in particular, has a profoundly mistaken ontology. There are no beliefs, $a$ fortiori no externally constituted beliefs. The only correct psychology is a scientific revision of common sense psychology, which quantifies exclusively over internal mental states (cf. e.g. Stich 1978, 1983). Members of the moderate camp accept that folk psychology has no profoundly mistaken ontology. There are indeed beliefs. However, ascriptions such as (7), interpreted in accordance with (the extension of) SSP, misrepresent to some extent the content of the beliefs ascribed and are therefore strictly speaking false. Concepts, such as Bert's and the medical experts' arthritis concepts, are ideolectical-they are conceptions-yet massively overlapping in the relevant respects, which is why we communicate successfully anyway. Since Burge's argument depends on CGC-the assumption that concepts are strictly speaking shared even if they are grasped in different ways - the argument is unsound and there is no social externalist threat to (folk) psychological explanation (e.g. Segal 2000, pp. 122-126; Bilgrami 1992, pp. 73-81).

22 This group too divides into two camps. The first camp (which includes Burge himself) argues that externally constituted beliefs $d o$ cause intentional behavior after all (e.g. Burge 1986b, 1995). Proponents of information theoretic accounts of content belong, in a sense, into this camp too, although their account is more a response to Putnam's different argument in support of (natural) externalism (e.g. Dretske 1993, 1995, Chap. 5; Stalnaker 1989, 1990, 1993). The second camp, defending the variety of so-called twofactor theories, denies this claim and argue that purely internal psychological states or factors, which are either themselves propositional attitudes or states or factors akin in structure to propositional attitudes, underlie externally constituted beliefs. And these underlying internal states or factors causally determine behavior. If so, the fact that externally constituted beliefs cannot themselves determine behavior is of minor significance (cf. for very different versions of this approach Fodor (1987, 1991), and Loar (1988)).

23 As are (12) and (13), as interpreted by us non-ideal scorekeepers who know the tale of Bert, according to Brandom.
} 
substitutional commitments regarding the term just prior to $t$-including Bert's deviant one from 'arthritis' to 'ailment striking joints and thighs' and the doctor's correct one from 'arthritis' to 'ailment striking the joints only'. Furthermore, the correlative de re ascriptions

Bert believes (prior to $t$ ) of arthritis that it afflicts the joints

and

(15) Bert's doctor believes (prior to $t$ ) of arthritis that it afflicts the joints

as interpreted by the ideal scorekeeper, are true as well, according to Brandom. Moreover, each captures from the idealized scorekeeper's perspective part of the normative statuses adopted in having the beliefs ascribed. The transparent occurrences of 'arthritis' in (14) and (15), as interpreted by the ideal scorekeeper, display the ideal scorekeeper's own acknowledged substitutional commitments regarding 'arthritis', hence what the ideal scorekeeper takes to be the substitution norms governing 'arthritis' - norms that, since they are objective, bind Bert and his doctor as well - and from which not only Bert's but also the doctor's respective acknowledged substitutional commitments presumably deviate to some extent. (Suppose the ideal scorekeeper is, while Bert's doctor is not, a leading expert in rheumatologic ailments.) Still, given PCD, (12)-(15) all specify the same belief, and in particular the same content (constituted in part by the single concept arthritis), though from three different perspectives of linguistic understanding. Thus, Bert and his doctor (as well as presumably the idealized scorekeeper) share that belief, although their respective grasps of its content differ. In other words, CGC is true, according to Brandom.

CGC commits Brandom to a version of semantic externalism, as he readily admits (e.g. Brandom 1994, p. 632; Brandom 2000b, pp. 359-360). According to Brandom, the constituents of the concepts arthritis and tharthritis are the objective semantic norms governing the use of 'arthritis' among speakers of English and Twenglish. Moreover, what constitutes Bert's grasp of arthritis and Twert's grasp of tharthritis prior to $t$ are, among other, their acknowledged substitutional commitments regarding 'arthritis' prior to $t$. Yet Bert's and Twert's acknowledged substitutional commitments per se (in abstraction from the semantic norms governing 'arthritis' in Bert's and Twert's respective linguistic communities) are indistinguishable prior to $t$ : prior to $t$, Bert and Twert are disposed to use the word 'arthritis' in exactly the same ways and to behave with respect to tokens of arthritis and tharthritis in exactly the same ways. Still, Bert grasps arthritis while Twert grasps tharthritis, and the beliefs in which these concepts figure are, accordingly, external to Bert and Twert.

Next, given PCD, Brandom's theory accords with the first half of (the extension of) SSP. Although we interpret oblique occurrences of terms in de dicto ascriptions based on what we take to be the ascribees' (as opposed to our own) acknowledged substitutional commitments, we also interpret, given PDC, these oblique occurrences as displaying the content of the beliefs ascribed as constituted by the very concepts that we take transparent occurrences of these terms to express. For 
example, although we-who know the tale of Bert and whose score kept on Bert thus reflects Bert's deviating acknowledged substitution-inferential commitment from 'arthritis' to 'ailment afflicting joints and thighs'-interpret the occurrence of 'arthritis' in the de dicto ascription (10) in accordance with Bert's deviant acknowledged substitution-inferential commitment, which we don't acknowledge ourselves, we also regard, given PCD, (10) and the correlative de re ascription (11) as individuating the same belief content. In this sense, we interpret the oblique occurrence of 'arthritis' in (10) as imputing to Bert the very concept arthritis that we take the transparent occurrence of 'arthritis' in (11) to express. ${ }^{24}$

Yet, of course, Brandom's theory is incompatible with the second half of (the extension of) SSP - the assumption that our interpretations of oblique occurrences of terms in a belief ascription do per se not capture the ascribee's grasp of the corresponding concepts. According to Brandom, we precisely interpret these occurrences such that they capture (what we take to be) the ascribee's grasp of these concepts, that is, (what we take to be) his acknowledged substitutional commitments, in accordance with our score. For example, according to Brandom's theory, once we are told the tale of Bert, our score registers Bert's mistaken acknowledged substitution-inferential commitment (prior to $t$ ) from 'arthritis' to 'ailment in joints and thighs', and we interpret the oblique occurrence of 'arthritis' in (10) accordingly. Hence, our interpretation of (10) not only imputes to Bert the concept arthritis, but also captures Bert's deviant grasp of arthritis.

(XIV) Intriguingly, due to this rejection of the second half of SSP, Burge's argument, when assessed from the perspective of Brandom's theory, establishes semantic externalism without the corollary. Due to this theory's agreement with CGC and the first half of SSP, the de dicto ascription (10), as interpreted by us, correctly ascribes a belief with an externally constituted content to Bert. Yet (10), so interpreted, also captures, due to Brandom's rejection of the second half of SSP, Bert's idiosyncratic grasp of this content and in particular his crucial idiosyncratic acknowledged substitution-inferential commitment regarding 'arthritis'. Thus, since acknowledged substitutional commitments are causal determinants of behavior, (10), as interpreted by us, also displays Bert's belief as a causal determinant of Bert's behavior, contra the corollary.

This seems to be an exciting, fresh perspective on Burge's (1979) argument. Brandom's theory, if true, would allow us to accept the best aspects of the two major response strategies to the argument while avoiding their difficulties. It would allow us to stick with the intuition that de dicto ascriptions such as (7) and (10), as

\footnotetext{
${ }^{24}$ However, PDC is obviously much stronger than the first half of SSP. For example, since according to PDC de re ascriptions individuate complete propositional contents, PDC seems to imply something like a Russellian identification of concepts with the referents of terms, while the first half of SSP is compatible with a Fregean distinction between concepts (senses) and referents. Moreover, the first half of SSP does not imply that de dicto ascriptions and their various de re counterparts all individuate the same belief. It only implies, when combined with the Fregean view, that, say, (10) represents the belief ascribed to Bert as involving the Fregean sense arthritis, while (11) — since it leaves open via which Fregean sense the belief ascribed to Bert refers to arthritis-does not fully individuate the content of the belief ascribed to Bert (cf. also Fn. 18).
} 
interpreted by us, are strictly speaking true-Bert has the beliefs (7) and (10) ascribe to him —and to embrace externalism. That is, it would spare us from having to grapple with any mismatches between (7) and (10), so interpreted, and the beliefs (if any) ascribed to Bert. Yet it would also allow us to stick with the intuition that these de dicto ascriptions figure in correct psychological explanations, since they also reveal the beliefs ascribed as causal determinants of behavior. Hence Brandom's theory would spare us from having to grapple with the awkward seeming corollary. Burge's (1979) argument, when assessed from the perspective of Brandom's theory, simply does not yield this corollary.

Along the way, Brandom's theory offers interesting replies to certain theoretical worries that seemingly speak against rejecting the second half of (the extension of) SSP - the crucial move that distinguishes this Brandomian reply to Burge's argument from other replies. Again, Burge justifies our interpretive practice in accordance with the second half of SSP by arguing that reinterpreting oblique termoccurrences in de dicto ascriptions such as to capture the ascribee's idiosyncratic grasp of concepts, would "proliferate terminology without evident theoretical reward" (Burge 1979, p. 94). Yet, first, such reinterpretations do not proliferate terminology, according to Brandom. In light of its intricacies-in particular its sophisticated theory of anaphora-Brandom's theory counts the oblique occurrence of, say, 'arthritis' in the de dicto ascription (10) as a recurrence of the same English term 'arthritis' that occurs transparently in the de re ascription (11), although we interpret the two occurrences differently. ${ }^{25}$ Second, such reinterpretive practice seems to offer rewards-though practical rather than theoretical ones-in that it allows us to make explicit aspects of our otherwise implicit recognition of differences in linguistic understanding, and thus to make such differences themselves the topic of our conversations. This explicitating role, Brandom claims, is a chief discursive function of de dicto and de re ascriptions.

(XV) Alas, while this response to Burge's argument might be available if we accept Brandom's theory of the belief ascriptions in isolation, that is, as a theory of interpretation for belief ascriptions apart from his doctrines of scorekeeping and the expressive role of belief ascriptions in discourse, we should, for two broad reasons, be skeptical about Brandom's theory of belief ascriptions, when placed in the context of these two core doctrines. First, if this theory in this context were true, the falsehood of the second half of SSP and the non sequitur of the corollary should spring right into our eyes and be largely uncontroversial among us. Yet in fact it seems obvious, and it is largely uncontroversial, among us that the second half of SSP is true and that Burge's (1979) argument, together with further widely accepted assumptions about mental causation, implies the corollary. ${ }^{26}$ Second, in the context of these two doctrines, the discursive rewards of interpreting belief ascriptions in the manner Brandom envisions, rather than in accordance with SSP, turn out to be, on

\footnotetext{
25 Cf. Fn. 16.

26 Again, the debate mainly focuses on whether Burge's argument is sound-specifically, on whether CGC is true-rather than on whether it is valid and whether it yields the corollary. Burge himself is among the few who denies that the corollary follows from his argument (e.g. Burge 1995).
} 
closer examination, zero, and they give us therefore neither theoretical nor prudential reasons to favor Brandom's proposed interpretive practice over SSP. Sections (XVI)-(XVIII) elaborate the former line of argument, Sects. (XIX)-(XXII) the latter.

(XVI) Like all speakers of English, we commentators on Burge's (1979) argument keep score on other speakers of English, according to Brandom. In particular, we keep score on fictitious English speakers such as Bert, which is why we could in principle communicate successfully with them-as we undoubtedly could. ${ }^{27}$ Moreover, we both acknowledge a substitution-inferential commitment from 'arthritis' to 'ailment striking the joints period' and know, given our exposure to the tale of Bert, that Bert acknowledges prior to $t$ a different and (indeed) incompatible one from 'arthritis' to 'ailment striking joints and thighs'. According to Brandom, our score registers this difference: our acknowledged substitutioninferential commitment goes into the book we keep on ourselves while Bert's different one goes into the book we keep on Bert. Thus, Brandom's theory predicts that our interpretations of the de dicto ascriptions (7) and (10) and the de re ascription (11) neatly reflect this difference: we interpret the oblique occurrence of 'arthritis' in (7) and (10) in accordance with Bert's deviant acknowledged substitution-inferential commitment and the transparent occurrence of 'arthritis' in (11) based on our own different acknowledged substitution-inferential commitment. Hence it predicts that we will, after our exposure to the tale of Bert, not interpret the occurrences of 'arthritis' in (7) and (10) in accordance with (the second half of) SSP, but such that they capture Bert's idiosyncratic grasp of arthritis. Especially once it is emphasized to us that (7) and (10), by contrast to (11), are already regimented and de dicto, these interpretations should force themselves upon us, since they merely mirror an aspect of our otherwise implicit score. Accordingly, Brandom's theory predicts that, once the second half of SSP is pointed out to us as a crucial assumption of Burge's argument, we will, after brief reflection, firmly and largely unanimously reject this assumption as misrepresenting our ordinary practice of interpreting belief ascriptions.

Moreover, since it is uncontroversial that a speaker's grasp of a concept-as opposed to the concept itself-constitutes, among other, his propensities to apply the concept in certain ways and hence is among the determinants of the speaker's linguistic and non-linguistic behavior, the non sequitur of the corollary should be fairly obvious to us as well. Few of us should be inclined to take it very seriously. Couched in Brandomian terms, it should be fairly uncontroversial among us that, since our interpretations of 'arthritis' in (7) and (10) capture Bert's acknowledged substitutional commitments regarding 'arthritis', which are in the causal order, the ascriptions (7) and (10), as interpreted by us, capture the belief ascribed to Bert as a causal determinant of Bert's linguistic and non-linguistic behavior.

\footnotetext{
27 Brandom emphasizes that his theory of scorekeeping cum belief ascriptions extends to our interpretation of texts generally (e.g. Brandom 2002, Chap. 3). He has mainly philosophical texts in mind, but his position clearly also includes fictitious conversations that someone narrates to us, and he would surely not deny that we keep score on fictitious persons such as Bert.
} 
Yet, of course, these things are far from uncontroversial. Instead, what seems initially obvious to us, and hard to reject even on reflection, is that the beliefs (7) and (10) ascribe to Bert are not only external to Bert but also (given certain further, natural, widely accepted assumptions about mental causation) inefficacious regarding Bert's intentional behavior. A little further reflection reveals that one main reason for this impression is that we interpret oblique term-occurrences in de dicto ascriptions such as (7) and (10) in accordance with (the extension of) SSP and, more specifically, based on our own understanding of (transparent occurrences of) these terms. And after still some further reflection, hardly anyone finds reasons for challenging SSP or a need to spring to its defense. Instead, virtually everyone agrees that (the extension of) SSP is a theoretically innocent, accurate description of our practice to interpret de dicto ascriptions. In short, it seems that the alternative to (the extension of) SSP Brandom's theory provides is mistaken: it misrepresents our ordinary practice of interpreting belief-talk in English.

(XVII) It may be objected that this attempt to rebut Brandom's theory in light of our response to Burge's (1979) argument falsely assumes that Brandom must hold that our interpretations of de re and de dicto ascriptions are by and large accessible - epistemically internal - to us, in the sense that we usually can find out what they are through reflection alone. Couldn't Brandom hold that we are often confused about our interpretive practice, in particular, that we think we interpret de dicto ascriptions in accordance with (the extension of) SSP when in fact we interpret them in accordance with his alternative?

Brandom neither does nor could easily hold this view. In general, although ease of access to one's own scorekeeping attitudes-one's acknowledgements and attributions of commitments - is presumably a matter of degree and context, and although scorekeeping attitudes may occasionally be suppressed in the Freudian sense, the bulk of the scorekeeping attitudes is epistemically internal, according to Brandom. To re-quote, he says, apropos acknowledged substitutional commitments, that "[a]ccording to one usage [of 'belief', viz. the de dicto usage], I believe only what I think I believe, what I take myself to believe. I do not believe things behind my back" (Brandom 1994, p. 507; cf. Sect. VII). ${ }^{28}$ Beliefs as ascribed by true de dicto ascriptions are what the believer takes them to be. In particular, their contents are what the believer takes them to be, that is, they are whatever substitutional commitments the believer acknowledges regarding these beliefs: these takings are 'not behind [the believer's] back' — by which Brandom presumably means that they

\footnotetext{
28 Similarly: "De dicto specifications of the content of another's thought depend on the inferences she is disposed to draw from it: what she thinks she is committing and entitling herself to thereby" (Brandom 2007, p. 669; his emphases). "[E]ach ascriber draws those auxiliary hypotheses from the facts as she takes them to be" (Brandom 2002, p. 101; his emphasis). "Looking at the other commitments an author would acknowledge tells an interpreter what the author took it that she was committing herself to by making a certain claim" (Brandom 2002, p. 96; his emphasis). "One engaged in this sort of [de dicto] interpretation is trying to specify the contents of commitments in a way that would be recognized and acknowledged as specifications of those contents by the one whose commitments they are" (Brandom 2002, p. 98; his emphases).
} 
are largely transparent to the believer. ${ }^{29}$ Of course, beliefs as ascribed by true de re ascriptions, and in particular the substitutional commitments the believer really adopts regarding these beliefs, as thus ascribed, are often largely beyond the believer's access through reflection alone, but his acknowledged commitments per se are not.

This is also what Brandom should say. At the core of his project is the idea that speakers are cognitively responsible for the commitments they acknowledge: due to their acknowledged commitments, speakers are proper subjects of critical appraisal, praise and blame, positive or negative sanctioning. Yet, notoriously, if speakers were fated to be largely and systematically misguided about what they take themselves to be committed to, or if such acknowledgements were largely subpersonal and beyond reflective access, it would be difficult to see how it could be proper to hold them responsible for them-a point that is familiar from debates on epistemic externalism. ${ }^{30}$ Thus, since it is by and large proper to hold speakers responsible for their acknowledged commitments, these acknowledgements should be construed as largely accessible to the speaker.

Such accessibility extends to one's attributions of commitments to others, according to Brandom: a scorekeeper has by and large accurate access to what commitments she takes others to acknowledge. Attributions of commitments are yet again something the scorekeeper is responsible for: it can be proper to challenge a scorekeeper's attributions on the grounds that they inaccurately reflect the commitments the other truly acknowledges (e.g. Brandom 1994, pp. 626-628). However, if such attributions were by and large beyond the scorekeeper's access, it would yet again be hard to see how the scorekeeper could properly be held accountable for them. Moreover, according to Brandom's reliabilist theory of empirical knowledge, an epistemic subject's dispositions to reliably form certain empirically contentful beliefs under certain perceptual circumstances justify, in an emphatically normative sense, these beliefs. Yet since such dispositions are per se naturalistic, and since their reliability is epistemically external to the subject, how can they have this normative status? According to Brandom, they have this status because actual and potential attributions of commitments to the epistemic subject by other scorekeepers, together with other factors, confer such normativity upon them (e.g. Brandom 1994, pp. 217-221; 2000a, pp. 117-122; 2011, pp. 130-132). However, such attributions could not have this normativity-conferring power, according to Brandom, if they were to the scorekeeper as epistemically external as the reliability of these dispositions per se are epistemically external to the epistemic

\footnotetext{
${ }^{29}$ Of course, Brandom has much latitude for accounting for this epistemically internal character of acknowledged commitments. He obviously does not need to maintain that acknowledged commitments are essentially phenomenally conscious, nor that one's access to them is epistemically incorrigible in all cases. Moreover, he does not need to commit himself to any specific theory about how such access is achieved-except that such access cannot in general be a matter of explicit higher-order thought.

30 Thus, externalists about knowledge/justification usually deny that meeting certain standards of cognitive responsibility is essential for possession of knowledge/justification, precisely because they deny that whether an epistemic subject meets the conditions for knowing/being justified is epistemically internal to the subject. For discussion cf. e.g. Prichard (2005, Chap. 7).
} 
subject. In sum, Brandom clearly does and should assumes that these attributions are by and large accessible to the scorekeeper on reflection. ${ }^{31}$

Yet such accessibility must not suddenly vanish when the scorekeeper makes aspects of them explicit via de re or de dicto ascriptions. More precisely, the scorekeeper's interpretations of transparent and oblique term-occurrences, reflecting her acknowledgements and attributions of substitutional commitments, must themselves by and large be accessible to her on reflection. After all, the purported power of de re and de dicto ascriptions to make these scorekeeping attitudes explicit consists in these interpretations of these term-occurrences based on these scorekeeping attitudes. If these interpretations were largely 'behind the scorekeeper's back', de re and de dicto belief ascriptions would be an unsuitable basis for expressing and critically appraising the scorekeeper's acknowledged and attributed substitutional commitments.

Yet it follows from all this that our responses to Burge's (1979) argument count as evidence against Brandom's theory of belief ascriptions. This theory predicts not only that we will interpret, for example, the occurrences of 'arthritis' in (7) and (10) in accordance with our attribution of the deviant acknowledged substitutioninferential commitment from 'arthritis' to 'ailment afflicting joints and thighs' to Bert, contra (the second half of) SSP, but also that we have access to this interpretation. What is more, we should be able to access this particular interpretation with special ease, since the very context-our exposure to Burge's (1979) argument-makes salient to us not only Bert's deviant acknowledged substitutional commitment from 'arthritis' to 'ailments afflicting joints and thighs' but also the fact that (7) and (10) are to be read de dicto. Thus, the fact that we so unanimously take ourselves to interpret (7) and (10) in accordance with the second half of SSP and, more specifically, based on our own understanding of (transparent occurrences of) 'arthritis', indicates that Brandom's theory provides a false picture of our ordinary practice of interpreting belief ascriptions.

(XVIII) Could Brandom maintain that we should not understand his theory descriptively, as an account of how we interpret de dicto ascriptions in fact, but prescriptively, as an account of how we should interpret them for the sake of avoiding certain philosophical problems? This response strategy would concede that our ordinary interpretive practice accords with SSP and emphasize that this practice, if left unexamined, raises philosophical problems such as the specter of the corollary of externalism and the problem how, given semantic holism, we manage to communicate successfully. It would then urge that since Brandom's theory,

\footnotetext{
31 "[Epistemic r]eliabilism deserves to be called a form of epistemological externalism, because assessments of reliability (and hence of knowledge) can turn on considerations external to the reasons possessed by the candidate knower himself. In those cases, such assessments concern the reasons possessed by the assessor of knowledge rather than by the subject of knowledge.... [T] hey should not therefore be seen as external to the game of giving and asking for reasons" (Brandom 2000a, p. 120). Passages such as these clearly commit Brandom to the view that assessments of reliability-which involve attributions of commitments as acknowledged to epistemic subjects—are 'possessed' by the assessor (the scorekeeper) in the sense of being epistemically internal to her. Because they are epistemic internality to the scorekeeper, they are not external to the game of giving and asking for reasons, despite being epistemically external to the epistemic subject.
} 
understood prescriptively, dissolves these problems, charity demands that we understand his theory prescriptively.

This reply should, I think, be of general interest. Although most commentators regard CGC as the more contentious assumption of Burge's (1979) argument, some have argued that we may at least sometimes interpret de dicto ascriptions roughly along the lines Brandom suggests, and contended that, given these interpretations on these occasions, a commitment to semantic externalism or the corollary (or both) may be avoided. ${ }^{32}$ Surely, those who favor such a response strategy to Burge's (1979) argument, as well as those who wish to reject the corollary in general, should take interest in Brandom's theory and mine it for materials to bolster their case.

However, this reply is not open for Brandom himself, given the specifics of his larger philosophical enterprise. A core claim of that enterprise is that our linguistic understanding is in fact holistic and constituted by our acknowledged substitutional commitments. Accordingly, Fodor's and LePore's challenge forces him to explain the undisputed abundance of our communicative successes, and his theory of scorekeeping cum belief ascriptions is his reply. We keep separate books of each other's acknowledged substitutional commitments implicitly in practice, thus capturing each other's varied linguistic understandings, and the central discursive role of de dicto and de re belief ascriptions is to make aspects of this otherwise implicit bookkeeping explicit. This explicitating role is vital for our discursive practice, as it allows us to make, for the sake of communicative repair or for hermeneutic purposes, our differences in linguistic understanding themselves the topic of the conversation. However, de dicto and de re belief ascriptions can play this explicitating role in our discourse only if we ordinarily interpret them in the way Brandom proposes. If Brandom's theory merely prescribed how we should interpret them, while conceding that we usually do not follow this prescription, belief ascriptions could not usually fulfill the primary discursive role his theory assigns to them. Thus, Brandom must insist that his theory describes, and does not merely prescribe, our ordinary practice of interpreting belief ascriptions.

(XIX) Yet, to turn to my second broad line of argument against Brandom's theory of belief ascriptions, do belief ascriptions really play their assigned explicitating role well-assuming Brandom's holism about linguistic understanding and his theory of scorekeeping, and disregarding for argument's sake the fact that our responses to Burge's argument support SSP? That is, do the alleged discursive benefits of belief ascriptions in the context of Brandom's overall project provide reasons, internal to that project, for favoring his theory of belief ascriptions over (the extension of) SSP? It turns out that they don't. Belief ascriptions have on closer inspection not even in that context the discursive benefits Brandom claims they have. Accordingly, considerations about such benefits do not even in that context provide reasons for favoring his theory of belief ascriptions over SSP.

To begin with, even according to Brandom's theory, we often interpret de dicto ascriptions in accordance with (the second half of) SSP. For example, we do so whenever we ascribe beliefs de dicto to strangers and groups. Consider

\footnotetext{
32 E.g. Bach (1988), in response to Burge's later (1986a) argument for social externalism.
} 


\section{(16) Arsky believes that Bert has arthritis}

and

(17) All physicians believe that arthritis strikes the joints only

Presumably, even according to Brandom's theory, you will interpret the oblique occurrences of 'arthritis' in (16) and (17) based on your own acknowledged substitutional commitments regarding the term, in accordance with SSP. ${ }^{33}$ In case of (16), you will do so simply because you know nothing about Arsky's idiosyncratic grasp of 'arthritis'-Arsky is a stranger to you. In case of (17), you will do so even if (what is impossible in practice) your score should neatly capture each physician's understanding of 'arthritis', because interpreting in accordance with (the union set of) all physicians' acknowledged substitutional commitments regarding 'arthritis' will yield no coherent interpretation-if, as is likely, at least two physicians' understandings of 'arthritis' diverge in some respect. In general, even according to Brandom's theory, we usually interpret obliquely occurring terms in de dicto ascriptions to strangers or groups based on our own acknowledged substitutional commitments, in accordance with SSP.

Thus, de dicto ascriptions may play the envisioned discursive role-to make explicit how the ascribee understands the obliquely occurring terms - only in some cases. However, they turn out to be ill-suited to play this role even in these cases. For example, suppose that my score captures Arsky's understanding of 'arthritis' perfectly while your score is blank in this regard-Arsky is a stranger to you. According to Brandom's theory, we should expect that my utterance of (16) to you under these circumstances reveals to you how Arsky understands 'arthritis' and thus provides us with a basis for conversing about his understanding of the term. Yet, of course, nothing like this happens. My utterance reveals to you that Arsky endorses the proposition that Bert has arthritis. In this regard, my utterance is truly informative to you. However, it leaves you in the dark about Arsky's understanding of 'arthritis'. Even if Brandom's theory is right (and SSP wrong), my utterance expresses Arsky's understanding only in the sense that my interpretation of 'arthritis' in my utterance captures Arsky's understanding of the term. Yet my utterance, so interpreted by me, leaves you (and any third person overhearing us) clueless about how I interpret the occurrence of 'arthritis' in it. Thus, since I already know how Arsky understands 'arthritis' and since you are left in the dark, my utterance of (16) is useless in our discourse as an expression of Arsky's understanding of 'arthritis'. Moreover, since you have nothing else to go by, you must presumably yet again interpret the occurrence of 'arthritis' in my utterance

\footnotetext{
33 Alternatively, perhaps you will interpret 'arthritis' in (16) and (17) based on what you regard as commonly acknowledged substitutional commitments regarding the term-if, say, you take your own understanding of the term to be too idiosyncratic_or, in case of (17), based on one particular physician's understanding of the term, if the context makes special provisions. In any case, your interpretations of (16) and (17) will not capture divergences in linguistic understanding in the way Brandom envisions.
} 
based on your own acknowledged substitutional commitments, in accordance with $\mathrm{SSP}^{34}$

(XX) The reasons why my utterance disappoints in playing the envisioned discursive role are not far to seek. When Brandom claims (I re-quote) that "the expressive function of de re ascriptions of propositional attitude is to make explicit which aspects of what is said express substitutional commitments that are being attributed [to the ascribee as acknowledged] and which express substitutional commitments that are undertaken [i.e. acknowledged by the ascriber]" (Brandom 1994, p. 505) he seems to suggests that oblique versus transparent term-occurrences in de dicto versus de re belief ascriptions 'express' attributed versus acknowledged substitutional commitments in the sense of his doctrine of logical expressivism. If this suggestion were correct, ascriptions such as my utterance of (16) should indeed play their envisioned discursive role rather well. Yet this suggestion is not correct.

In general, according to Brandom's doctrine of logical expressivism, the role of logical vocabulary is to allow us to express-make explicit-in the form of claims what we otherwise only do implicitly in practice. It allows us, in this sense, to codify "knowing how in the form of knowing that" (Brandom 2002, p. 8). Conditional claims are Brandom's paradigm case. We antecedently acknowledge in practice inferential commitments concerning certain pairs of atomic sentences ' $\mathrm{S}_{1}$ ' and ' $\mathrm{S}_{2}$ '. Through subsequent mastery of the conditional (a piece of logical vocabulary) we may then express, in the sense of logical expressivism, these inferential commitments themselves in the form of conditional claims - claims to the effect that if $S_{1}$ then $S_{2}$ - thus making these inferential commitments themselves the common topic of a conversation. ${ }^{35}$ For example, if I express my acknowledged inferential commitment from 'Bert has arthritis' to 'Bert has an ailment afflicting the joints' to you by asserting 'If Bert has arthritis then he has an ailment afflicting the joints', my assertion amounts to the claim that Bert's having arthritis implies Bert's having an ailment afflicting the joints, according to Brandom's theory of the conditional. This codification in the form of a claim allows you to pick up what is claimedregardless of your own antecedent take on the matter-and thus to acknowledge the inferential commitment in question yourself in response, to ask me to back it up, to challenge it, etc. (e.g. Brandom 2002, p. 60).

Given Brandom's theory of scorekeeping, belief ascriptions are indeed expressive in this sense, and Brandom is thus right to regard 'believes that' as a piece of logical vocabulary (e.g. Brandom 1994, p. 530). Antecedently, a scorekeeper

\footnotetext{
34 Third persons whose score already comprises (mis)information regarding Arsky's understanding of 'arthritis' will interpret my utterance based on their score, according to Brandom's theory. However, they too obviously learn nothing new in this regard from my utterance. Incidentally, my uttering (16) to you under the circumstances arguably counts as an instance of miscommunication by Brandom's own lights: I interpret 'arthritis' in it in accordance with Arsky's understanding of the term, you interpret it based on your own understanding, while third persons interpret it in accordance with their own various scores on Arsky. Thus, we understand my utterance in different ways and do, accordingly, miscommunicateunless each of us keeps not only score on Arsky but also score on how anyone else keeps score on Arsky.

35 Obviously, conditionals as expressions of (material) inferential relations are not conditionals as the truth-functional devices of classical propositional logic - a point that Brandom is happy to concede (e.g. Brandom 1994, pp. 111-116).
} 
attributes in practice to a linguistic peer, $\mathrm{H}$, a commitment to make an assertion that $p$ (she attributes to $\mathrm{H}$ an assertional or doxastic commitment regarding $p$ ). Through subsequent mastery of the locution 'believes that' she may then express, in the sense of logical expressivism, this otherwise implicit attribution in the form of a claim-a claim to the effect that $H$ believes that $p$-thus making H's assertional commitment regarding $p$ itself the common topic of the conversation. ${ }^{36}$ For example, my assertion of (16) expresses the claim that Arsky believes (acknowledges a commitment to assert) that Bert has arthritis, which allows you to pick up what is claimed and thus to make this attribution to Arsky yourself in response, to ask me to back it up, to challenge it, etc.

However, even if Brandom's theory of belief ascriptions is true, performances of de dicto belief ascriptions do not express, in the sense of logical expressivism, the ascriber's attributions of substitutional commitments as acknowledged to the ascribee, that is, they do not in this sense make the ascribee's linguistic understanding explicit. They "express" these attributions only in the sense that the ascriber interprets the oblique term-occurrences in accordance with these attributions, but not also in the sense that they codify these attributions in the form of claims. My utterance of (16), for instance, does not amount to a claim to the effect that Arsky understands 'arthritis' such and so or that Arsky acknowledges such and such substitutional commitments regarding 'arthritis', hence it fails to allow you to pick up Arsky's purported understanding of 'arthritis', to attribute to Arsky the relevant substitutional commitments as acknowledged yourself in response, to ask me to back up my claim, to challenge it, etc. Thus, since de dicto belief ascriptions, as interpreted in accordance with Brandom's theory, fail to express attributed substitutional commitments in the form of claims, interpretation in this manner fails to give belief ascriptions the discursive significance Brandom claims they have.

(XXI) This is not to say that, given Brandom's semantic theory, we may not sometimes via belief ascriptions make claims about an ascribee's understanding of certain terms. Consider

(18) Bert believes that arthritis is an ailment striking joints and thighs

and

(19) Bert believes that having arthritis implies having an ailment striking joints and thighs

Given Brandom's inferential role semantics, both ascriptions express (insinuate) in the form of claims that Bert acknowledges a substitution-inferential commitment from 'arthritis' to 'ailment striking joints and thighs'. However, they do so not because we interpret the oblique occurrences of these terms in (18) and (19) based on what we take to be Bert's acknowledged substitutional commitments, but rather because, thanks to the workings of 'believes that' and the oblique occurrences of the 'is' of identity, existential quantification ('an'), and 'implies', (18) and (19) as

\footnotetext{
36 Obviously, this view about the expressive function of belief-talk rests on controversial assumptions about the relation between belief and assertion, which we need not to discuss here.
} 
wholes express (insinuate) in the form of claims that Bert acknowledges the substitution-inferential commitment in question. And they do so even if we interpret the oblique occurrences of 'arthritis' and 'ailment striking joints and thighs' in accordance with SSP. Interpretation in accordance with Brandom's theory contributes yet again nothing to this expressive power of (18) and (19).

Note, however, that, given Brandom's semantic theory, belief-talk is inessential for expressing in the form of claims how someone understands certain terms. The claims

(20) Bert understands 'arthritis' to mean an ailment striking joints and thighs

and, indeed,

(21) Bert acknowledges a substitution-inferential commitment from 'arthritis' to 'ailment striking joints and thighs'

express the relevant aspect of Bert's understanding of 'arthritis' just as well as (18) and (19)—or even better-without ascribing belief. Moreover, interpreting the quoted or unquoted occurrences of 'arthritis' and 'ailment striking joints and thighs' in (20) and (21) in accordance with what we take to be Bert's understanding of the terms, rather than SSP, obviously contributes yet again nothing to the expressive power of (20) and (21).

(XXII) In conclusion, we thus see that the discursive benefits of interpreting belief ascriptions in accordance with Brandom's theory rather than SSP are nil even in the context of Brandom's inferential role semantics, his theory of scorekeeping, and his theory of logical expressivism. Thus even this context gives us no reason to favor his theory of belief ascription over SSP. Accordingly, since reflection on Burge's (1979) argument for social externalism and the responses to it in the literature provides reason against this theory and in favor of (the extension of) SSP, Brandom should drop the former and endorse the latter.

If Brandom endorses SSP, what are the implications for his overall project? With respect to his theory of scorekeeping cum theory of expressing differences in understanding, these implications are obviously significant. Brandom has to develop a different strategy for squaring his holism about understanding with our manifold communicative successes and our ability to make differences in understanding explicit. That is, he either needs to develop a different theory of how we express different aspects of our otherwise implicit score, or-more radically-revise his theory of scorekeeping qua implicit, separate bookkeeping itself. ${ }^{37}$ However, these

\footnotetext{
37 For a listing of alternative strategies and brief arguments why they are unattractive, cf. Wanderer (2008, pp. 147-151). One potentially promising strategy, which is not on Wanderer's list, is to reject the assumption that communicative success is a matter of shared, or sufficiently overlapping, or separately tracked de facto linguistic understanding, but is instead a matter of shared recognition of various bits of discourse as tokenings of the same term-hence of shared recognition that these bits ought to be understood in the same way by everybody. On the one hand, the shared recognition of this obligation may allow interlocutors to negotiate a shared partial understanding of the term, if so needed for achieving the broader goals of the conversation. On the other hand, such shared recognition may per se suffice for qualifying a conversation as successful.
} 
implications do not affect Brandom's semantic project and its correlative theory of linguistic understanding per se. Even if SSP enshrines our ordinary practice of interpreting belief talk, the meaning of (non-logical, singular or general) terms may still consist in the substitution norms governing use of these terms, in accordance with Brandom's inferential role semantics, and a speaker's linguistic understanding of these terms may still be a matter of acknowledging substitutional commitments.

Acknowledgments I would like to thank Gary Ebbs, Sandy Goldberg, and Kevin Sharp, as well as an anonymous referee for very helpful comments on earlier drafts of this paper.

Open Access This article is distributed under the terms of the Creative Commons Attribution License which permits any use, distribution, and reproduction in any medium, provided the original author(s) and the source are credited.

\section{References}

Bach, K. (1987). Thought and reference. Oxford: Oxford University Press.

Bach, K. (1988). Burge's new thought experiment. Back to the drawing room. Journal of Philosophy, 85, 88-97.

Bilgrami, A. (1992). Belief and meaning. The unity and locality of content. Oxford: Blackwell.

Brandom, R. B. (1994). Making it explicit. Reasoning, representing, and discursive commitment. Cambridge, MA: Harvard University Press.

Brandom, R. B. (2000a). Articulating reasons. An introduction to inferentialism. Cambridge, MA: Harvard University Press.

Brandom, R. B. (2000b). Facts, norms, and normative facts. A reply to Habermas. European Journal of Philosophy, 8, 356-374.

Brandom, R. B. (2002). Tales of the mighty dead. Historical essays in the metaphysics of intentionality. Cambridge, MA: Harvard University Press.

Brandom, R. B. (2007). Inferentialism and some of its challenges. Philosophy and Phenomenological Research, 74, 651-676.

Brandom, R. B. (2011). Perspectives on pragmatism. Classical, recent, and contemporary. Cambridge, MA: Harvard University Press.

Burge, T. (1977). Belief de re. Journal of Philosophy, 74, 338-362.

Burge, T. (1979). Individualism and the mental. Midwest Studies, 6, 73-121.

Burge, T. (1986a). Intellectual norms and foundations of mind. Journal of Philosophy, 83, 697-720.

Burge, T. (1986b). Individualism and psychology. Philosophical Review, 95, 3-45.

Burge, T. (1995). Reply: Intentional properties and causation. In C. Macdonald \& G. Macdonald (Eds.), Philosophy of psychology. Debates in psychological explanation (pp. 226-235). Oxford: Blackwell.

Cresswell, M. (1985). Structured meanings. The semantics of propositional attitudes. Cambridge, MA: MIT Press.

Dretske, F. (1993). The nature of thought. Philosophical Studies, 70, 185-199.

Dretske, F. (1995). Naturalizing the mind. Cambridge, MA: Bradford/MIT.

Fodor, J. A. (1987). Psychosemantics. The problem of meaning in the philosophy of mind. Cambridge, MA: Bradford/MIT.

Fodor, J. A. (1991). A modal argument for narrow content. Journal of Philosophy, 88, 5-26.

Fodor, J. A., \& LePore, E. (1992). Holism. A shopper's guide. Cambridge, MA: Blackwell.

Goldberg, S. (2002). Do anti-individualistic construals of propositional attitudes capture the agent's conceptions? Nous, 36, 597-621.

Kaplan, D. (1968). Quantifying in. Synthese, 19, 178-214.

Kimbrough, S. (1998). Anti-individualism and Fregeanism. Philosophical Quarterly, 48, 470-482.

Lewis, D. (1979). Scorekeeping in a language game. Journal of Philosophical Logic, 8, 339-359. 
Loar, B. (1988). Social content and psychological content. In H. Grimm \& D. D. Merrill (Eds.), Contents of thought (pp. 99-110). Tucson: University of Arizona Press.

McKinsey, M. (1999). The semantics of belief ascriptions. Nous, 33, 519-557.

Patterson, S. (1990). The explanatory role of belief ascriptions. Philosophical Studies, 59, 313-332.

Prichard, D. (2005). Epistemic luck. Oxford: Oxford University Press.

Quine, W. V. (1956). Quantifiers and propositional attitudes. Journal of Philosophy, 53, 177-187.

Quine, W. V. (1960). Word and object. Cambridge, MA: MIT Press.

Segal, G. M. A. (2000). A slim book about narrow content. Cambridge, MA: MIT Press.

Stalnaker, R. (1989). On what's in the head. Philosophical Perspectives, 3, 287-316.

Stalnaker, R. (1990). Narrow content. In C. A. Anderson \& J. Owens (Eds.), Propositional attitudes. The role of content in logic, language, and mind. Stanford: CSLI.

Stalnaker, R. (1993). Twin earth revisited. Proceedings of the Aristotelian Society, 93, 297-311.

Stich, S. (1978). Autonomous psychology and the belief-desire thesis. Monist, 61, 573-591.

Stich, S. (1983). From folk psychology to cognitive science. Cambridge, MA: Bradford MIT.

Wanderer, J. (2008). Robert Brandom. Montreal: McGill-Queen's University Press. 